Acta Technologica Agriculturae 2

Nitra, Slovaca Universitas Agriculturae Nitriae, 2016, pp. 43-48

\title{
INFLUENCE OF BELLOWS SETTING ON ITS SPRING RATE AND ON TEMPERATURE ADJUSTMENT OF ELECTROMECHANICAL THERMOSTATS
}

\author{
Peter HAAS*, Milan KADNÁR, František TÓTH, Juraj RUSNÁK, Dušan NÓGLI \\ Slovak University of Agriculture in Nitra, Nitra, Slovak Republic
}

\begin{abstract}
The precision and stability of adjusted temperatures are critical requirements for electromechanical thermostats. The key element in meeting the requirement is a thermostat bellows. It is a convertor of pressure into force that actuates the mechanical system of the thermostat. Convolutions enabling the axial movement of the bellows cause that the bellows is partly behaving as a spring. Therefore, the bellows has its own spring rate. The setting of the bellows spring rate influences the critical parameters of the thermostat. The aim of the article is to find the difference between the setting done by bellows producer and setting done by thermostat producer and its influence on the thermostat adjustment.
\end{abstract}

Keywords: bellows; spring rate; temperature adjustment; bellows setting

When sensing the temperature by an electromechanical thermostat, the temperature of the sensor element creates a pressure of the vapour charge inside the element (Althouse et al., 2004). This pressure has to be converted into force that actuates the mechanical system of the thermostat. In electromechanical thermostats, there is a component used to convert pressure into force. That thermostat component could be a diaphragm (membrane) or bellows. In this paper, we will focus on the bellows.

\section{Material and methods}

The bellows for electromechanical thermostats are usually made of CuSn6 bronze by a multi-step production process. CuSn6 bronze provides good formability for the production process and right mechanical properties for the final bellows. It is recognized for good wall thickness distribution (Faraji et al., 2009; Kučera and Chotěborský, 2014; Majdan et al., 2010). Some sources mention generally four steps: deep drawing, ironing, tube-bulging, folding (Lee, 2002). The production of the seamless bellows is better described by six steps (Sigma-Netics, 2015). For better understanding we have added a final step of bellows setting (Figure 1). Bulging, folding and spring back (Faraji et al., 2009) are suboperations of hydroforming.

After hydroforming and trimming, there needs to be done an additional operation on the raw bellows in order to stabilize the spring rate.

The stabilization of spring rate is achieved by mechanical compression and possible subsequent application of the vacuum. The bellows is forced to 'blocking length Lb'. It is a measure of compression when all convolutions will make a contact to its adjacent convolutions (Tököly et al., 2013; Tóth et al., 2014). This setting operation is the first operation of the bellows and it provides the basic and most significant stabilization of spring rate. After the setting bellows spring rate causes bellows to stabilize at 'free length Lob' (Danfoss A/S, 2013).

The change of convolutions shape after setting makes the spring rate stabilized (Figure 3). Further steps of stabilization can be made during the thermostat production process by pressurizing and vacuuming the bellows. But it will never reach the blocking length again, as there are created safety stops to prevent the mechanical damage to the bellows.

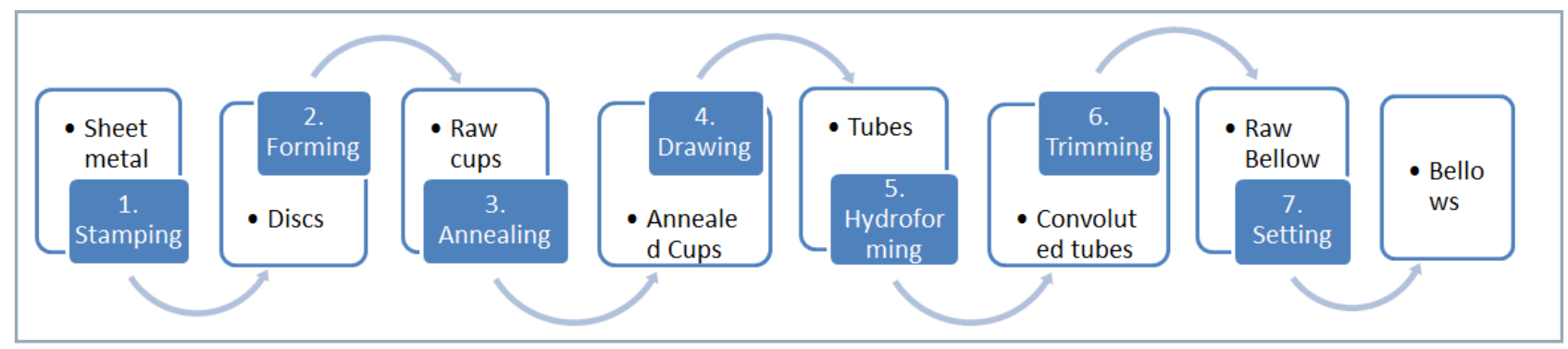

Figure 1 Bellows production flow chart

Source: author

Contact address: Peter Haas, Slovak University of Agriculture in Nitra, Faculty of Engineering, Department of Machine Design, Tr. Andreja Hlinku 2, 94976 Nitra, Slovak Republic, e-mail: xhaas@is.uniag.sk 


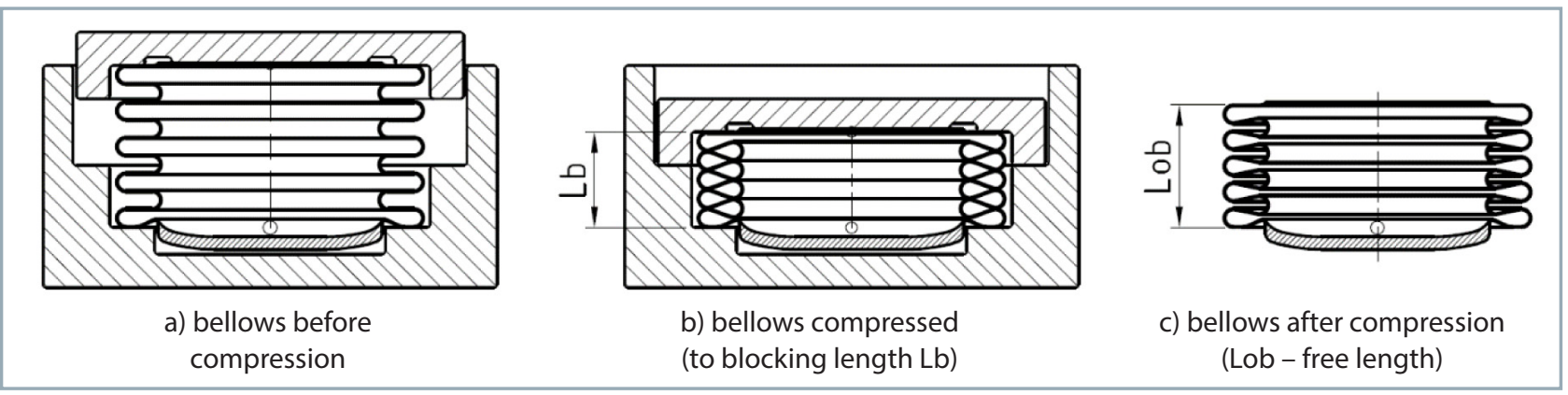

Figure 2 Bellows setting

Source: Danfoss A/S
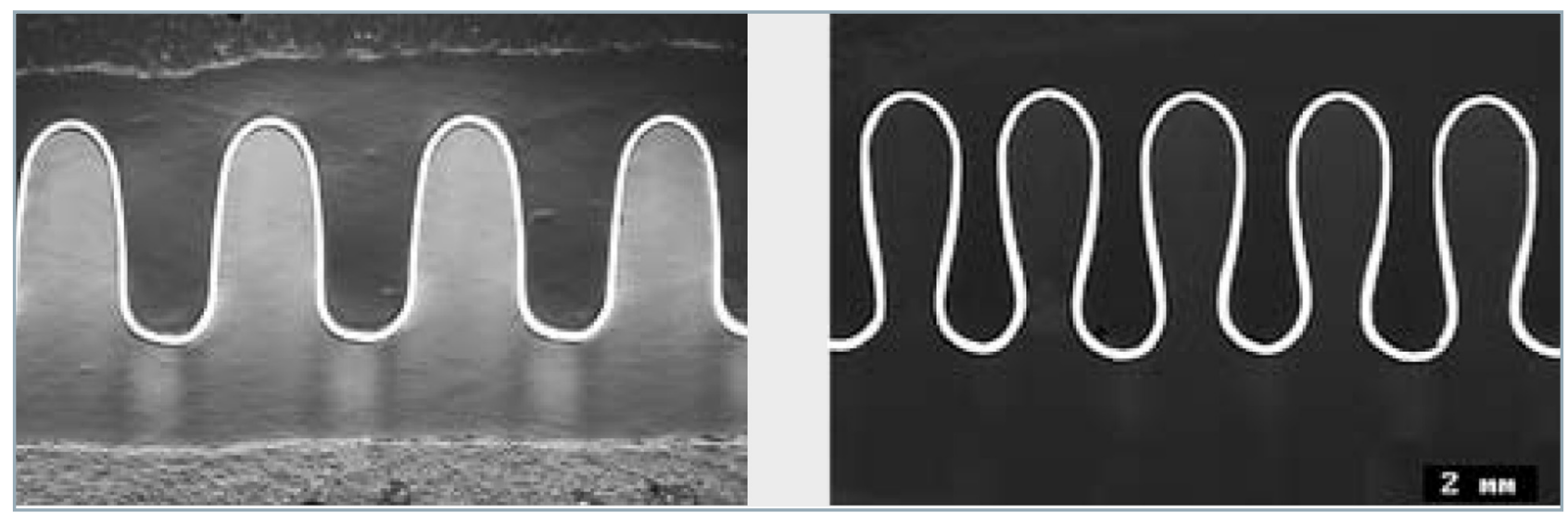

Figure 3 Change of convolutions shape after setting operation

Source: Witzenmann, 2015

Force generated by bellows can be calculated as:

$$
F_{B}=C_{B} \times s_{B}+A_{B} \times p
$$

where:

$F B$ - force generated by bellows (N)

$C_{B}$ - spring rate $(\mathrm{N} / \mathrm{mm})$

$s_{B}$ - bellows stroke $(\mathrm{mm})$

$A_{B}$ - bellows area $\left(\mathrm{mm}^{2}\right)$

$p$ - pressure $(\mathrm{Pa})$

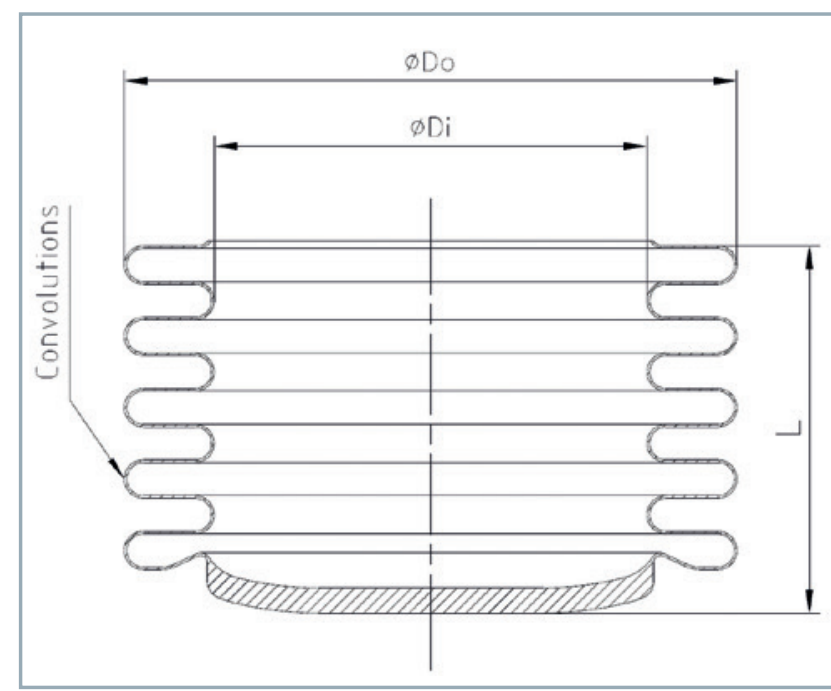

Figure 4 Basic dimensional parameters of bellows Source: author
We can consider the bellows area $A B$ as constant as it is given by the design of the bellows (2). Bellows area equations are empirical, but can be validated by measurement. Different sources are providing slightly different equations (Sigma-Netics, 2015):

$$
A_{B}=\frac{\pi}{12}\left(D_{o}^{2}+D_{o} \times D_{i}+D_{i}^{2}\right)
$$

where:

$D_{o} \quad$ - outer diameter $(\mathrm{mm})$

$D_{i} \quad$ - inner diameter ( $\left.\mathrm{mm}\right)$

As the bellows consists of convolutions that act like a spring, it has its own spring rate. The bellows spring rate is determined by material, wall thickness, the outer and inner diameter of convolutions and the number of convolutions (Sigma-Netics, 2015). The equation for spring rate is as follows:

$$
C_{B}=\frac{\Delta F}{\Delta s}
$$

where:

$\Delta F \quad-$ force differential $(\mathrm{N})$
$\Delta s \quad$ - displacement $(\mathrm{mm})$

From Eq. (1) and Eq. (2) and assumptions above we can see that the bellows spring rate stability and its stability has a direct influence on the force that actuates the mechanical system of the thermostat. The stability of the bellows spring rate therefore becomes critical for adjusted temperatures and their stability during operation. 


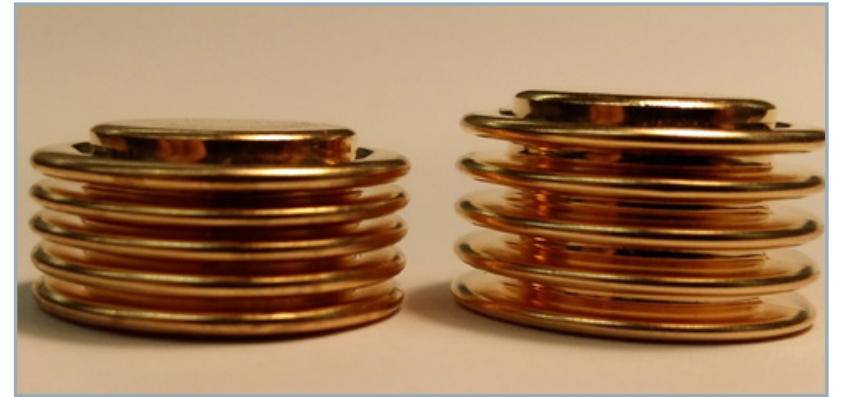

Figure 5 Bellows after (left) and before (right) setting Source: author

There are two possibilities of bellows delivery. It can be delivered with or without setting from bellows manufacturer (Figure 4). The bellows without setting has to be set during the thermostat production. The aim of this paper is to find out whether setting by bellows manufacturer provides higher quality and what is the difference to bellows delivered in raw condition and set during the thermostat production. The focus will be on the quality of temperature adjustment and evaluation of differences between the batches.

The test was performed in the Danfoss Appliance Controls facilities. Danfoss Appliance Controls currently uses bellows without setting. Setting is done by the gripper and subsequent application of vacuum in the bellows element machine during the bellows element subassembly manufacturing.

\section{Experimental procedure I}

We have chosen to execute the comparative test of two batches of the thermostat. Batch size was set to 100 samples in order to have enough data for statistical evaluation. The batch of thermostats without set bellows was compared with the other batch with bellows set by the manufacturer. Parameters of the thermostats (077B3543) and for adjustment were completely the same. The only difference was in processing the bellows in the bellows element machine. The goal was to compare the temperature adjustment of both batches and their statistical parameters. The evaluation of temperature test shall prove whether bellows setting by its manufacturer provides better quality regarding the statistical parameters of the adjusted thermostats.

The samples of bellows for the spring rate measurement were taken from both batches. Test was performed on the force measurement system in a programmed mode. A program was made to actuate already set bellows and from read values of force and displacement (stroke) calculate its spring rate $C_{B}$, as in Eq. (3).

\section{Thermostat sample preparation}

Thermostat samples were divided into two batches by 100 samples. Samples were marked at the bellows element machine and consequently numbered at control bath before the temperature testing:

1. Batch no. 1 (bellows delivered without manufacturer setting). The reference batch containing bellows without setting was produced with machine gripper setup in the way that the gripper made bellows setting. The centre of the gripper contained a pin whose relative height to the bellows seat was set to secure the bellows to be compressed to blocking length. The pin touched the bellows end (crown) and compressed it towards the seat where the bellows was placed and subsequent vacuum was applied.

2. Batch no. 2 (bellows delivered with manufacturer setting). The second batch containing set bellows by manufacturer was produced in the same machine. The centre pin of the gripper was removed before production of the batch to avoid secondary setting.

\section{Tested thermostats}

The thermostats $077 \mathrm{~B} 3543$ belonging to the $077 \mathrm{~B} 6$ family of the Danfoss 077B thermostat were tested. 077B6 are constant cut-in thermostats used to control a single compressor cooling circuit of double-door appliance (freezer + cooler):

- Adjusted in cold position

- Charged with R290 media

- Cut-in temperature $+3.0^{\circ} \mathrm{C}$

- Cut-in tolerance $\quad \pm 1.0^{\circ} \mathrm{C}$

- Cut-out temperature $-30.0^{\circ} \mathrm{C}$

- Cut-out tolerance $\quad \pm 1.5^{\circ} \mathrm{C}$

\section{Bellows used}

The bellows used in the test was 077B0632 manufactured by Hengda Metal Bellows Co. Ltd., currently owned by Sigma-Netics. The main parameters of 077B0632 (Danfoss $A / S, 2005)$ are as follows:

- $D_{o}=18.4 \pm 0.4 \mathrm{~mm}$

- $D_{i}=13.0 \pm 0.4 \mathrm{~mm}$

- Five convolutions

- CuSn6 tin bronze material

- $C_{B}=9.8 \pm 4 \mathrm{~N} / \mathrm{mm}$

\section{Adjustment of samples}

The adjustment of both batches was done in adjusting bath no. 4 in standard sequence. Both batches followed each other and then were separated according to marking for control bath tests.

\section{Control bath test}

The control bath test checks temperatures of the thermostat after adjustment and makes the statistical evaluation. The batch size of one control bath test is maximum 20 samples. Thermostats are seated in the ramp and electrical connection is made to its contact system terminals. Sensors of thermostats are dipped into the alcohol tank. After the start of the test control bath is changing the temperature of the alcohol inside of the tank according to the algorithm and requested temperature parameters. It checks the state of the thermostats contact systems (Cut-in/Cut-out) and registers the temperature when the contacts system status has changed. As the thermostat and its temperatures are influenced by barometric pressure, registered temperatures are recalculated according to current barometric pressure. When the test is completed, control bath creates a report with all registered temperatures and calculated statistical parameters for the sample batch. 


\section{Criteria for 077B3543 approval}

- Cut-in $C_{p k} \geq 1.00$ (corresponds to cut-in tolerance $\pm 1.0^{\circ} \mathrm{C}$ )

- Cut-out $C_{p k} \geq 1.33$ (corresponds to cut-out tolerance $\pm 1.5^{\circ} \mathrm{C}$ )

- No temperature out of tolerance $\left(C_{p}-\right.$ process capability; $C_{p k}-$ process capability index)

\section{Experimental procedure II}

The samples (10 for each batch) of bellowsforthespring ratemeasurement were taken from the same delivery of both bellows batches. Test was performed on the force measurement system in a programmed mode. The program was made to actuate already set bellows and from registered values of force and displacement (stroke) to calculate its spring rate $\mathrm{CB}$.

\section{Tested bellows}

- Batch no. 1 - 077B0632 bellows set in thermostat production at bellows element machine M1 (gripper + vacuum).

- Batch no. 2 - 077B0632 bellows set by manufacturer.

The bellows of the batch no. 1 were taken out from the machine roundtable after setting was done. Setting was done in the manual step mode of the machine.

\section{Spring rate measurement and calculation}

The following equipment was used for bellows spring rate measurement and calculation:

- Force measurement system MECMESIN Imperial 1000, serial no. 04-1031-07.

- Load cell - MECMESIN Imperial 50N, serial no. 04-0378-07.

\section{Results and discussion}

The partial test results for both batches were consolidated into one report for each batch. Statistical parameters and histograms for the whole batch sizes were calculated and visualized. A summary table was created in order to better communicate the results.

The spring rate of the bellows set by manufacturer (batch no. 2) is in average slightly lower than the one set in thermostat production (batch no. 1). It means that it is softer than the batch

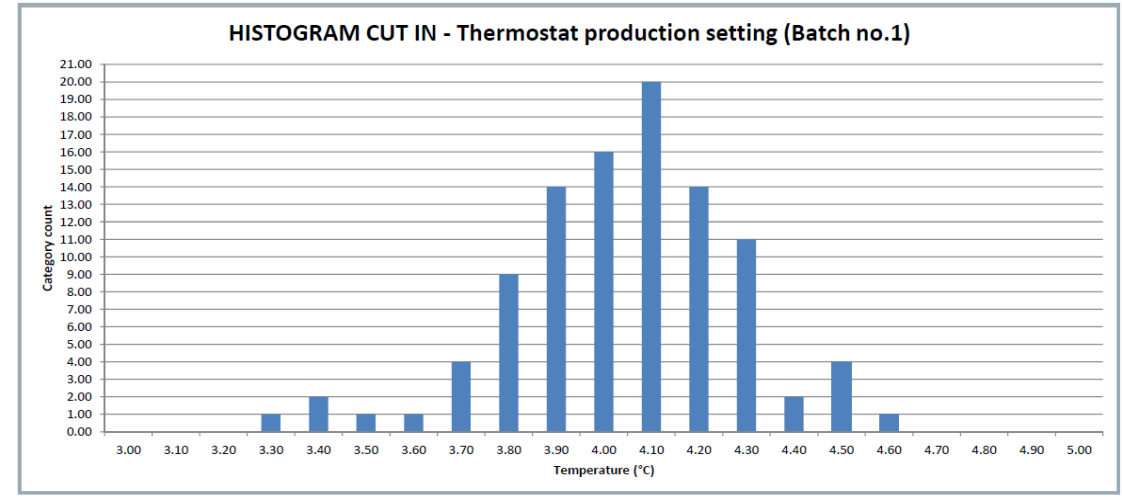

Figure 6 Histogram for cut-in (batch no. 1)

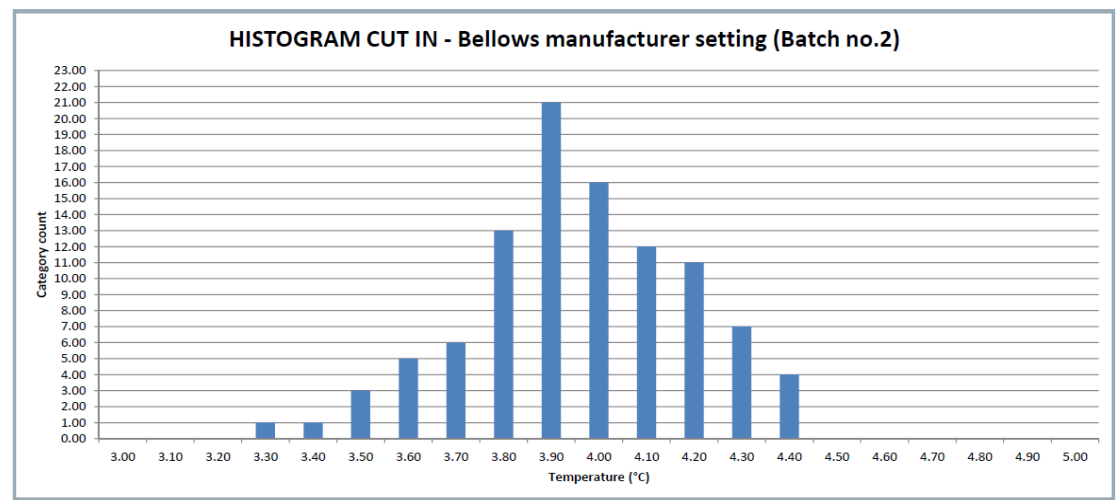

Figure 7 Histogram for cut-in (batch no. 2)

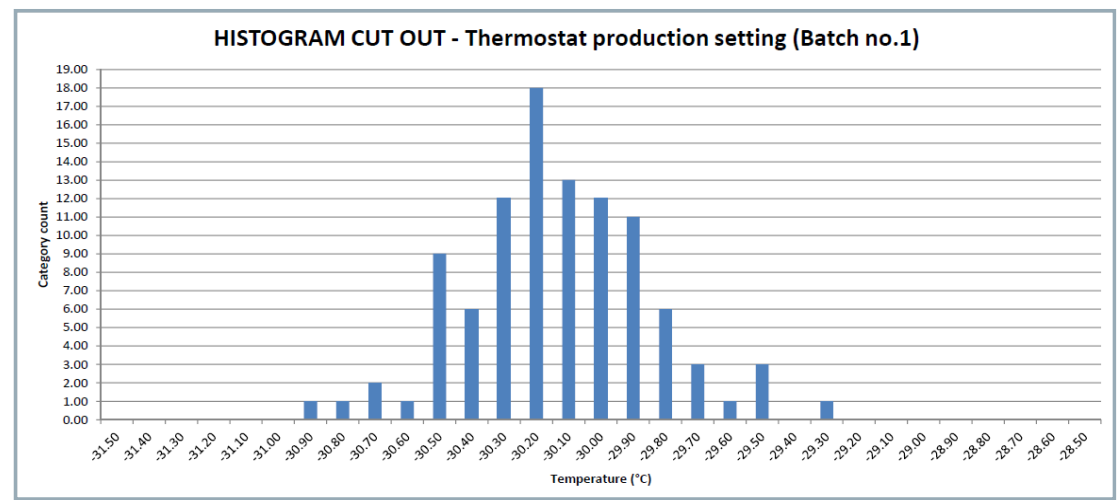

Figure 8 Histogram for cut-out (batch no. 1)

no. 1 and providing less force from its spring characteristic. More important is that the spring rate of the bellows set by manufacturer (batch no. 2) has lower standard deviation (Table 1). It could be due to the level of vacuum used for setting or adjustment of the gripper pin.

All the 200 samples of 2 batches passed the $100 \%$ control bath test for temperature check. There was no sample adjusted out of tolerance or near the tolerance limit. All temperature parameters fulfilled the requested criteria of $C_{p k}$ index.
Comparing the $C_{p}$ index, the results of both batches are very similar (Table 2). The difference of $C_{p}$ is insignificant for cut-in temperature and slightly higher for bellows production setting at cut-out temperature adjustment. Regarding the $C_{p k}$ index for cut-in temperature, we can see that a higher value was reached by bellows set by manufacturer. Cut-in temperature is in average only $0.01{ }^{\circ} \mathrm{C}$ warmer than nominal by manufacturer setting, compared to $0.09{ }^{\circ} \mathrm{C}$ warmer by production setting. This position closer to nominal makes the value of $C_{p k}$ index higher for manufacturer 


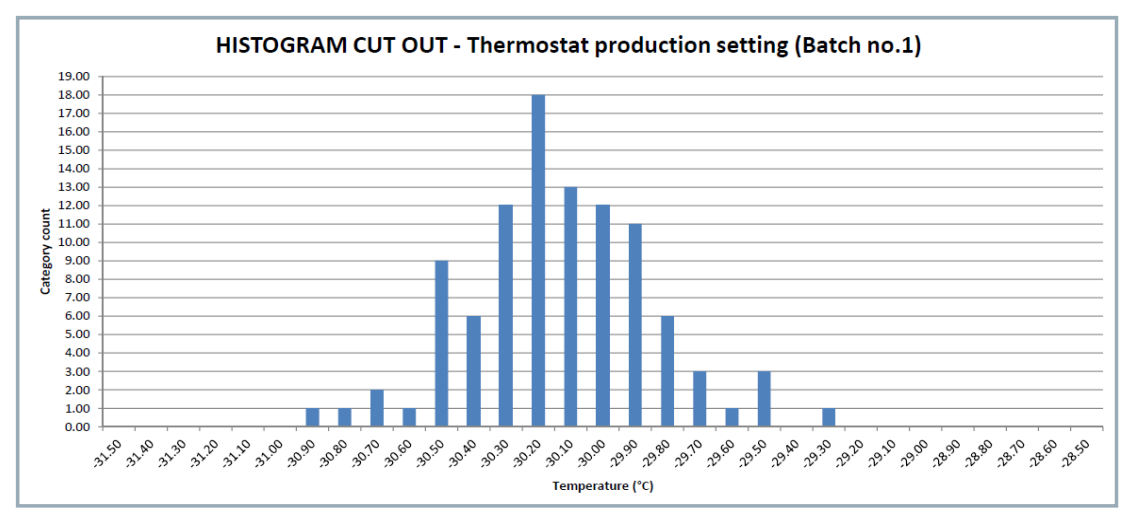

Figure 9 Histogram for cut-out (batch no. 2) setting and very close to its $C_{p}$ index value.

Regarding cut-out temperature adjustment, production setting showed better performance due to lower standard deviation $(0.287$ vs 0.304$)$ and insignificantly better position related to nominal $\left(-0.08{ }^{\circ} \mathrm{C}\right.$ vs $\left.+0.09^{\circ} \mathrm{C}\right)$. This is a point of interest as the total difference between mean values of batches is $0.17{ }^{\circ} \mathrm{C}$, while the same adjustment parameters were applied. Production set batch was adjusted $-0.08{ }^{\circ} \mathrm{C}$ colder than nominal,

Table 1 Bellows spring rate $\left(C_{B}\right)$ results summary

\begin{tabular}{|c|c|c|c|c|c|c|c|c|c|c|c|}
\hline \multicolumn{6}{|c|}{ Batch no. 1} & \multicolumn{6}{|c|}{ Batch no. 2} \\
\hline \multicolumn{6}{|c|}{ Bellows setting in thermostat production } & \multicolumn{6}{|c|}{ Bellows setting by bellows manufacturer } \\
\hline Parameter & $F_{1}$ & $s_{1}$ & $\mathbf{F}_{2}$ & $s_{2}$ & CB & Parameter & $\mathbf{F}_{1}$ & $s_{1}$ & $\mathbf{F}_{2}$ & $s_{2}$ & $C B$ \\
\hline Units & $\mathbf{N}$ & $\mathbf{m m}$ & $\mathbf{N}$ & mm & $\mathrm{N} / \mathrm{mm}$ & Units & $\mathbf{N}$ & $\mathbf{m m}$ & $\mathbf{N}$ & mm & $\mathrm{N} / \mathrm{mm}$ \\
\hline Sample 1 & 7.65 & 1.01 & 20.05 & 2.37 & 9.134 & Sample 1 & 8.08 & 1.01 & 20.15 & 2.32 & 9.214 \\
\hline Sample 2 & 5.65 & 1.01 & 20.07 & 2.63 & 8.903 & Sample 2 & 6.29 & 1.01 & 20.18 & 2.69 & 8.240 \\
\hline Sample 3 & 8.77 & 1.01 & 20.19 & 2.13 & 10.191 & Sample 3 & 7.64 & 1.01 & 20.26 & 2.47 & 8.641 \\
\hline Sample 4 & 7.91 & 1.01 & 20.13 & 2.26 & 9.757 & Sample 4 & 7.20 & 1.00 & 20.17 & 2.53 & 8.475 \\
\hline Sample 5 & 5.53 & 1.01 & 20.15 & 2.89 & 7.775 & Sample 5 & 8.75 & 1.01 & 20.11 & 2.22 & 9.351 \\
\hline Sample 6 & 8.23 & 1.00 & 20.09 & 2.38 & 8.606 & Sample 6 & 6.50 & 1.01 & 20.19 & 2.59 & 8.619 \\
\hline Sample 7 & 6.01 & 1.01 & 20.13 & 2.79 & 7.930 & Sample 7 & 6.42 & 1.00 & 20.39 & 2.64 & 8.547 \\
\hline Sample 8 & 6.40 & 1.01 & 20.14 & 2.47 & 9.413 & Sample 8 & 6.28 & 1.01 & 20.23 & 2.80 & 7.784 \\
\hline Sample 9 & 7.00 & 1.00 & 20.25 & 2.55 & 8.549 & Sample 9 & 5.67 & 1.01 & 20.37 & 2.81 & 8.147 \\
\hline Sample 10 & 6.42 & 1.01 & 20.23 & 2.56 & 8.881 & Sample 10 & 7.08 & 1.01 & 20.12 & 2.58 & 8.333 \\
\hline Mean & & & & & 8.914 & Mean & & & & & 8.535 \\
\hline Sdev & & & & & 0.755 & Sdev & & & & & 0.471 \\
\hline
\end{tabular}

Table 2 Summary of results

\begin{tabular}{|l|c|c|c|}
\hline \multicolumn{3}{|l|}{ 077B3543 Batch no. 1 } \\
\hline Bellows setting \\
\hline \multicolumn{3}{|l|}{ In thermostat production } \\
\hline Parameter & Cut-In & Cut-Out & Unit \\
\hline UTL & 5.0 & -28.5 & ${ }^{\circ} \mathrm{C}$ \\
\hline NOM & 4.0 & -30.0 & ${ }^{\circ} \mathrm{C}$ \\
\hline LTL & 3.0 & -31.5 & ${ }^{\circ} \mathrm{C}$ \\
\hline Mean & 4.09 & -30.08 & ${ }^{\circ} \mathrm{C}$ \\
\hline Sdev. & 0.235 & 0.287 & N/A \\
\hline 3 * Sdev. & 0.704 & 0.861 & N/A \\
\hline CP & 1.42 & 1.74 & N/A \\
\hline CPK & 1.29 & 1.65 & N/A \\
\hline$\Delta$ Mean To NOM & 0.09 & -0.08 & ${ }^{\circ} \mathrm{C}$ \\
\hline
\end{tabular}

\begin{tabular}{|l|c|c|c|}
\hline 077B3543 Batch no. 2 \\
\hline Bellows setting \\
\hline \multicolumn{3}{|l|}{ By bellows manufacturer } \\
\hline Parameter & Cut-In & Cut-Out & Unit \\
\hline UTL & 5.0 & -28.5 & ${ }^{\circ} \mathrm{C}$ \\
\hline NOM & 4.0 & -30.0 & ${ }^{\circ} \mathrm{C}$ \\
\hline LTL & 3.0 & -31.5 & ${ }^{\circ} \mathrm{C}$ \\
\hline Mean & 4.01 & -29.91 & ${ }^{\circ} \mathrm{C}$ \\
\hline Sdev. & 0.227 & 0.304 & N/A \\
\hline $3 *$ Sdev. & 0.682 & 0.912 & N/A \\
\hline CP & 1.47 & 1.64 & N/A \\
\hline CPK & 1.45 & 1.55 & N/A \\
\hline \hline$\Delta$ Mean To NOM & 0.01 & 0.09 & ${ }^{\circ} \mathrm{C}$ \\
\hline
\end{tabular}

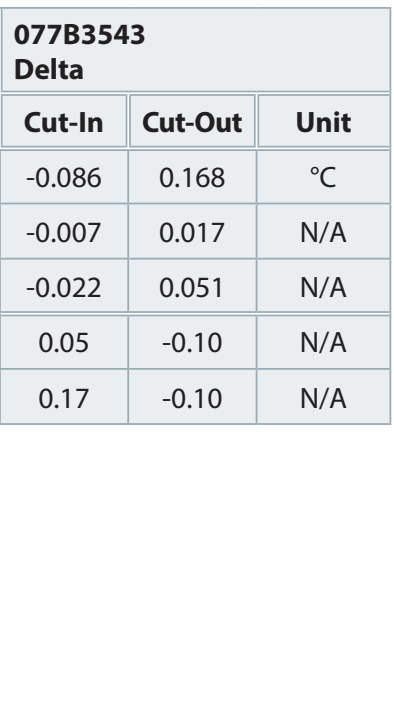


while manufacturer set batch $+0.09{ }^{\circ} \mathrm{C}$ warmer than nominal in average.

From the temperature test summary (Table 2) we can see that the quality of bellows setting is more sensitive at low (cut-out) temperatures. It has higher influence in final force generated by bellows at lower temperatures (pressures). The higher the variation of bellows spring rate, the higher variation is added to force generated by bellows. As this force actuates the mechanical system, variation has to be compensated by thermostat adjustment.

Bellows set by manufacturer has lower variation and shall provide better base for the temperature adjustment of the thermostat. Nonetheless, this variation (Table 1) can be to a certain extent eliminated at thermostat adjustment, as shown by temperature tests (Table 2). Despite slight differences in mean values of batches, both ways of bellows setting can be considered equal from the temperature adjustment point of view. Most of the variances areeliminated during the adjustment of thermostat temperatures.

\section{Conclusion}

The advantage of bellows setting by manufacturer is that thermostat producer receives the final bellows set by experts. Disadvantage is in a higher unit price of set bellows as there is one operation more during the bellows production process. The disadvantage of setting the raw bellows in the thermostat production is needed allocation of resources for setting operation. Differences in temperature values can be assigned to different approach to setting. Bellows manufacturers use a spring mechanism while Danfoss AP sets to a constant height by rigid pin located at the machine gripper and subsequent vacuum application.

As the bellows one of the manufacturers mentions (Witzenmann, 2015), spring rate has a strong dependence on wall thickness and convolution height rather than stresses. Therefore, it reacts sensitively to any small change in bellows geometry. Manufacturers and users of bellows for high precision devices shall focus on the stabilization of spring rate by wall thickness precision and setting process stability. It will result in a positive effect of the final product and its production.

\section{Acknowledgment}

This work was carried out at the Danfoss Appliance Controls facilities in Zlaté Moravce, Slovak Republic. Knowledge, material and technical support is gratefully acknowledged.
Supported by the Ministry of Education of the Slovak Republic, project VEGA 1/0227/15 'Study of tribological characteristics of new high hard coatings on materials suitable for gearings'.

\section{References}

ALTHOUSE, A. D. - TURNQUIST, C. H. - BRACCIANO, A. F. 2004. Modern refrigeration and air conditioning. $18^{\text {th }}$ ed. Tinley Park, IL : Goodheart-Wilcox Company Inc, 2004.

DANFOSS A/S. 2005. Bellows 077B. Nordborg : Danfoss A/S, 2005.

DANFOSS A/S. 2013. Instruction for calculation, assembly, adjustment and control of 077B. Nordborg : Danfoss A/S, 2013.

FARAJI, G. - MASHADI, M. M. - NOROUZIFARD, V. 2009. Evaluation of effective parameters in metal bellows forming process. In Journal of Materials Processing Technology, vol. 209, 2009, no. 7, pp. 3431-3437.

KUČERA, M. - CHOTĚBORSKÝ, R. 2013. Analysis of the process of abrasive wear under experimental conditions. In Scientia Agriculturae Bohemica, vol. 44, 2013, pp. 102-106.

LEE, S. W. 2002. Study on the forming of the metal bellows. In Journal of Materials Processing Technology, vol. 130, 2002, pp. 47-53.

MAJDAN, R. - TKÁČ, Z. - TULÍK, J. - VOZÁROVÁ, V. - CHRASTINA, J. - ŠIMOR, R. - KOSIBA, J. 2010. The methods for smart inspection of biodegradable transmission oil of tractor (Metode za brzu kontrolu ekološkog transmisionog ulja traktora). In Savremena Poljoprivredna Tehnika, vol. 36, 2010, pp. 276-284.

SIGMA-NETICS. 2015. Technical resources: White papers: Designing with metal bellows. [Online]. Available at: http:// www.sigmanetics.com/technical-resources/white-papers [Accessed 8 January 2016].

TÓTH, F. - RUSNÁK, J. - KADNÁR, M. - ČAVOJSKÝ, P. 2014. Effect of selected ecological lubricants on the wear of defined sliding bearing. In Acta Technologica Agriculturae, vol. 17, 2014, no. 1, pp. 13-16.

TÖKÖLY, P. - BOŠANSKÝ, M. - MALÝ, V. 2013. Metodika opredelenija zakalennogo sloja $v$ nezvolventnom zubčatom zeceplenii. In Visnik Nacional'novo Techničnovo Universitetu "XIII", vol. 41, 2013, pp. 148-153.

WITZENMANN. 2015. Downloads: 0441 Metal bellows manual. [Online]. Available at: http://www.witzenmann.sk/sk/downloads/ brochure.cmd [Accessed 8 January 2016]. 